\title{
Air due to Glue: Spontaneous Pneumothorax in a Young Adult with Glue Sniffing
}

\author{
Deebya Raj Mishra, ${ }^{1}$ Narendra Bhatta, ${ }^{1}$ Bidesh Bista, ${ }^{1}$ Puru Koirala, ${ }^{1}$ Ramhari Ghimire ${ }^{1}$ \\ 'Division of Pulmonary, Critical Care \& Sleep Medicine, Department of Internal Medicine, B. P. Koirala Institute of Health \\ Sciences, Dharan, Nepal.
}

\begin{abstract}
Solvent abuse, as inhalant specially, in the form of low cost adhesives like dendrite is common in low income countries among children and the teens. This habit is often a stepping stone to harder drugs. The neurological and neuropsychological effects of solvent abuse are well explored. But the respiratory effects are often overlooked. In this report, we present a case of a 19 year old gentleman, with regular history of sniffing of commercial "glue" compounds. This patient presented with right sided chest pain and chest $\mathrm{x}$-ray showed a right sided pneumothorax. The pulmonary barotrauma, possibly due to increased intra-alveolar pressure, during the sniffing process can lead to alveolar rupture and in turn, pneumothorax. In the absence of other risk factors for Pneumothorax, the link between inhalant abuse and respiratory complications has to be explored in patients with history of such abuse.
\end{abstract}

Keywords: inhalant abuse; pneumothorax; solvent.

\section{INTRODUCTION}

Glue sniffing, also known as solvent abuse is defined as the deliberate inhalation of volatile substances for the purpose of recreational self-intoxication. ${ }^{1}$ It is a common problem in low income countries. In Nepal, a 2002 study showed that $51.7 \%$ of the street children were sniffing glue. ${ }^{2}$ Another study done in Dharan showed that $72.9 \%$ of the street children were using glue. ${ }^{3}$ Glue sniffing is often a stepping-stone to harder drugs. Though much is known about the increased risk for serious neurological, and neuropsychological impairments, ${ }^{4}$ neurological, and neuropsychological impairments. While animal research suggests that exposure to organic solvents (especially toluene the pulmonary effects of solvent abuse are often overlooked. Here we present a case of a young male, with history of solvent abuse who presented with pneumothorax.

\section{CASE REPORT}

A 19 year old man with no significant past medical history presented to the emergency department with right sided chest pain while coughing for 2-3 days. He admitted to cigarette smoking from the age of 11 years and has smoked equivalent to 4 pack years. He also gave the history of regular glue sniffing for the last 5-6 years period. The patients' height was $162.5 \mathrm{~cm}$ and he had a body mass index (BMI) of $24.6 \mathrm{~kg} / \mathrm{m}^{2}$. He used "dendrite" and other liquid adhesives as inhalant and predominantly used sniffing technique with occasional use of bagging technique. He predominantly used glue which is a cynoacrylate based adhesive. The frequency of use was 4-5 times in a day.

Correspondence: Dr. Deebya Raj Mishra, Division of Pulmonary, Critical Care \& Sleep Medicine, Department of Internal Medicine, B.P. Koirala Institute of Health Sciences, Dharan, Nepal. Email: debyaraj@ gmail.com, Phone: +977-9851134760. 
Clinically, his trachea was central but he had reduced air entry on the right side with a hyper-resonant percussion note. His oxygen saturations were $95 \%$ on air but he was tachypnoeic with a respiratory rate of 28 per minute. He was normotensive and had a pulse rate of 110 beats per minute.

His chest $\mathrm{X}$-ray showed a right pneumothorax and given the degree of breathlessness and size of pneumothorax, a $28 \mathrm{Fr}$ chest drain was inserted with no complications (Figure 1). Radiology post drain insertion showed reexpansion of the affected lung (Figure 2).

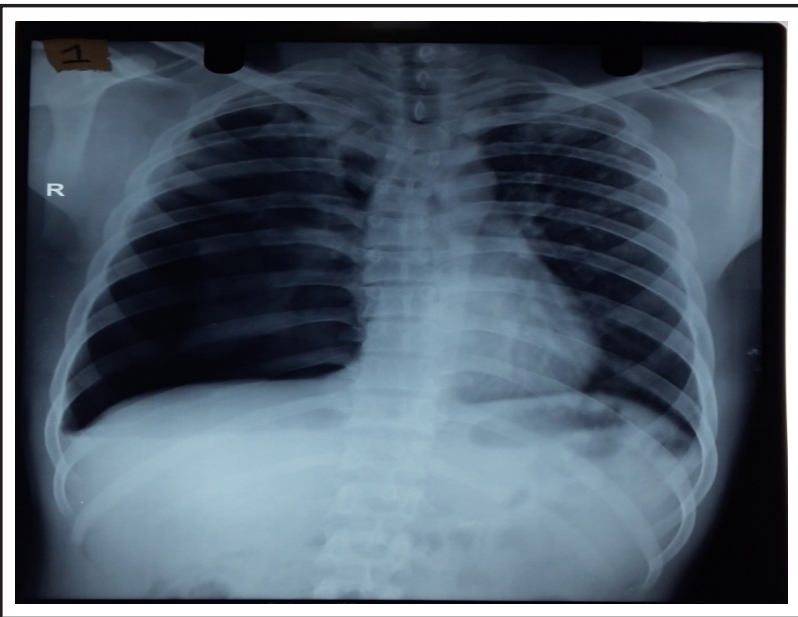

Figure 1. Right Pneumothorax.

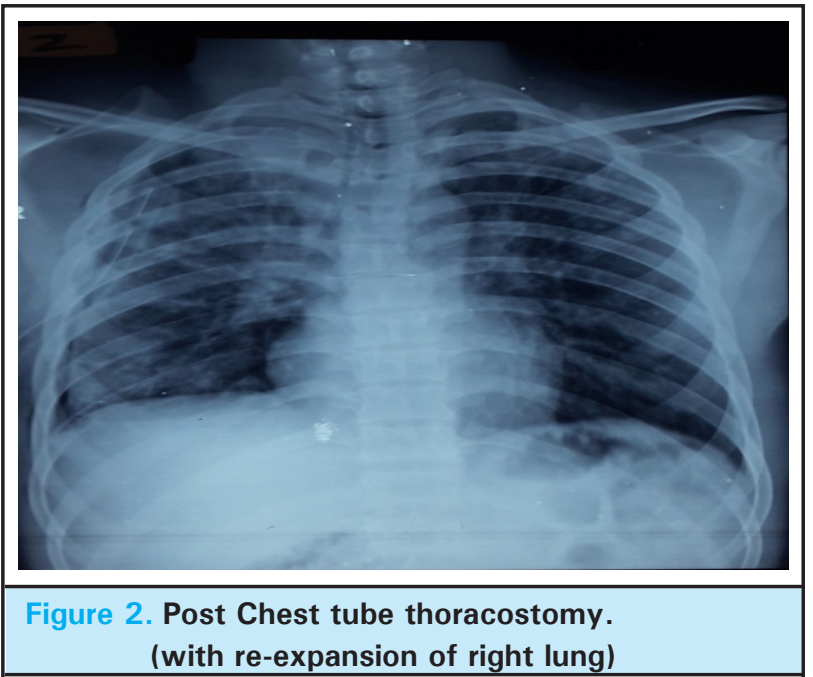

However from the $3^{\text {rd }}$ day of admission patient developed chest infection with upper lobe infiltrates and right pleural effusion. Chest computerised tomography showed right pleural effusion with pneumothorax and surgical emphysema on the right lateral chest wall (Figure 3).

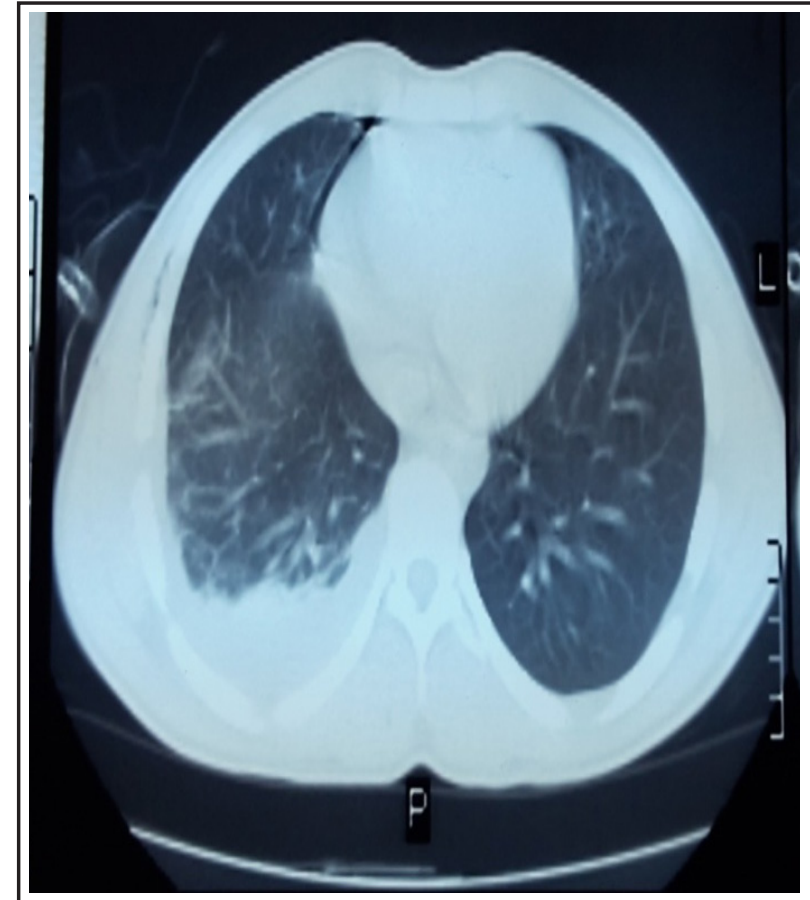

Figure 3. CT chest showing right Pleural effusion and Pneumothorax.

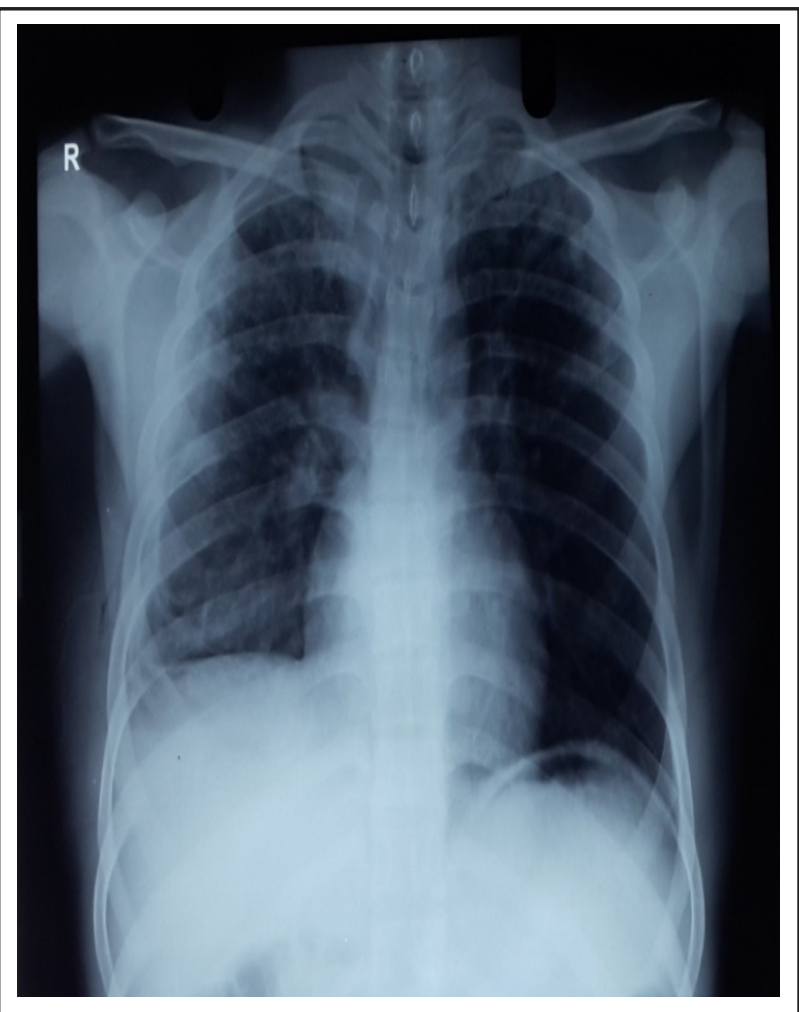

Figure 4. Chest X-ray at discharge. (No evidence of Pneumothorax)

He was subsequently managed with i.v antibiotics and once the chest tube drain was less than $50 \mathrm{ml} /$ day the chest tube was taken out. Chest $x$-ray post removal showed no evidence of pneumothorax, but there was 
blunting of right costophrenic angle with upper zone infiltrates and evidence of surgical emphysema (Figure 4). The patient was discharged on oral antibiotics and called on follow up. On follow up after 2 weeks the patient was asymptomatic. The Chest CT did not show any obvious bulla. Since the effusion and infiltrates developed 3 days after chest tube insertion, we attributed the same to chest infection following tube thoracostomy. The cause of pneumothorax was attributed to sniffing of glue. Genetic tests were not done due to lack of availability.

\section{DISCUSSION}

There are three different ways in which glue can be inhaled each having its own physiology. Sniffing (nasal inhalation) of vapours directly from an open container or a surface soaked with the substance; huffing (oral inhalation) from a rag or cloth soaked in a volatile substance that is held over the mouth or nose; or Bagging which involves breathing in and out of a paper or plastic bag filled with a small amount of a volatile substance. $^{1}$

Toluene and xylene, found in many types of glues and solvents, are the most common aromatic hydrocarbons of abuse. The readily available consumer products used are glues, cement, paint, lacquers, gasoline, drycleaning fluids, correction fluids, and butane lighters. Though the concentration of the substance inhaled from sniffing is lower than that from huffing, the physiology of inhalations in all three techniques are different. Acute pulmonary effects namely bronchospasm, asphyxia and aspiration pneumonitis are recognized complications of inhalant abuse that will manifest as cough, wheezing and dyspnoea. ${ }^{1}$ Long term damage to the respiratory system resulting from chronic glue sniffing includes panacinar emphysema and Goodpasture's syndrome..$^{5,6}$ A few reports of pneumothorax or pneumomediastinum following combined use of marijuana, heroine, or

cocaine have been published. ${ }^{7-10}$ The use of a single drug has been related to barotrauma. We present an adolescent male who developed this complication after alternate use of marijuana and cocaine without positive pressure devices. The increasing problem of drug abuse in the adolescent population in the United States is known to all of us. Clinicians who deal with adolescent patients should include questioning about drug abuse in the standard evaluation of chest pain."

"Two cases of spontaneous pneumothorax after repeated inhalation of cocaine and forced aspiration of marijuana smoke, respectively, are presented. The absence of pneumomediastinum and associated subcutaneous emphysema in both cases is stressed. Inspiratory manipulations against resistance are assessed as potential etiological factors, although the coexistence of other pneumothorax predisposing factors seems to be necessary. "Anales de medicina interna (Madrid, Spain: 1984). However, to our knowledge, there have been no reports linking glue sniffing to pneumothorax.

Our patient used to "sniff" glue forcefully, a mechanism akin to use of cocaine. We hypothesize that the mechanism of pneumothorax would be similar to the mechanism in cocaine. The pulmonary barotrauma seems to be related to the increase in the intra-alveolar pressure caused either by (1) deep inhalation followed by a Valsalva maneuver (often performed to increase the effect of the inhaled substance) or (2) severe cough triggered by the inhalant. ${ }^{10}$ This leads to alveolar rupture with air dissecting through the peribronchiolar connective tissue into the mediastinum, pericardium, pleural space, or subcutaneous soft tissues.

Interestingly the risk of pneumothorax seems to be increased by tobacco smoke, ${ }^{11}$ and there have been reports of synergistic action with cannabis and smoking. ${ }^{10}$ A similar synergism cannot be ruled out between cigarette smoking and glue sniffing.

Glue sniffing being common in the low income countries, this cause has to be ruled out before labelling a case as "Primary" spontaneous pneumothorax and proper counselling with regards to abstinence from glue done in all the cases.

\section{Conflict of Interest: None.}

Consent: JNMA Case Report Consent Form was signed by the patient and the original is attached with the patient chart.

\section{REFERENCES}

1. Tulsidas H. Glue Sniffing: A Review. Proc Singapore Healthcare. 2010;19(4). [Full Text | DOI]

2. Rai A, Ghimire KP, Shrestha P, Tuladhar S. Glue Sniffing among Street Children in Kathmandu Valley. Child Workers in Nepal Concerned Centre. 2002. [ Full Text]
3. Thapa K, Ghatane S, Rimal S. Health problems among the street children of Dharan municipality. Kathmandu Univ Med J. 2010 Feb;7(3):272-9. [리리 | DOI]

4. Yücel M, Takagi M, Walterfang M, Lubman DI. Toluene misuse and long-term harms: A systematic review of the neuropsychological and neuroimaging literature. Neurosci Biobehav Rev. 2008;32(5):910-26. [PubMed | DOI] 
5. Schikler KN, Lane EE, Seitz K, Collins WM. Solvent abuse associated pulmonary abnormalities. Adv Alcohol Subst Abuse. 1984;3(3):75-81. [PubMed | DOI]

6. Robert R, Touchard G, Meurice JC, Pourrat O, Yver L. Severe Goodpasture's syndrome after glue sniffing. Nephrol Dial Transplant. 1988;3(4):483-4. [PubMed | DOI]

7. Luque MA, Cavallaro DL, Torres M, Emmanual P, Hillman JV. Pneumomediastinum, pneumothorax, and subcutaneous emphysema after alternate cocaine inhalation and marijuana smoking. Pediatr Emerg Care. 1987 Jun;3(2):107-9. [PubMed I DOI]

8. Herrejón Silvestre A, Blanquer Olivas J, Simo Mompo M, Ruiz Montalt F, Núñez Sánchez C, Chiner Vives E. Pneumothorax due to drug inhalation. An Med Interna. 1992 Mar;9(3):137-9. [PubMed]
9. Mattox KL. Pneumomediastinum in heroin and marijuana users. JACEP. 1976 Jan;5(1):26-8. [PubMed | DOI]

10. MillerWE,SpiekermanRE,HepperNG.Pneumomediastinum resulting from performing Valsalva maneuvers during marihuana smoking. Chest. 1972 Aug;62(2):233-4. [ [PubMed | DOI]

11. Bense L, Eklund G, Wiman LG. Smoking and the increased risk of contracting spontaneous pneumothorax. Chest. 1987 Dec;92(6):1009-12. [PubMed | DOI] 